Int. J. Electrochem. Sci., 14 (2019) $8699-8708$

\title{
Corrosion and Electrochemical Impedance Properties of Ti6Al4V Alloy and Ti-3Zr-2Sn-3Mo-25Nb Alloy Treated by Micro-arc Oxidation Process
}

\author{
Mei Yang ${ }^{1, *}$,Wenhao Zhang ${ }^{1}$, Jin Chen ${ }^{2}$, Yang Li $i^{2}$, Tingyu Huang ${ }^{1}$, Ning Tang ${ }^{1}$, Pengcheng Li $^{1}$ \\ ${ }^{1}$ Materials Science and Engineering, Southwest Petroleum University, Cheng'du 610500, China \\ ${ }^{2}$ Sichuan petroleum Enginering Construction Co.,Ltd, Cheng'du 610000, China \\ *E-mail: 380056676@qq.com
}

doi: $10.20964 / 2019.09 .09$

Received: 19 April 2019 / Accepted: 18 June 2019 / Published: 31 July 2019

To analyse the effects of micro-arc oxidation (MAO) on the different substrates, TLM (Ti-3Zr-2Sn$3 \mathrm{Mo}-25 \mathrm{Nb}$ ) and TC4 (Ti-6Al-4V) were oxidized in an aqueous electrolyte including $\mathrm{KH}_{2} \mathrm{PO}_{4}$, $\mathrm{Ca}\left(\mathrm{CH}_{3} \mathrm{COO}\right)_{2}$ and EDTA-2Na. The bore diameters of the two kinds of material were both between 0.5 and $2 \mu \mathrm{m}$ in ceramic film surfaces. The MAO coatings consisted of two layers: a dense inner layer and a porous outer layer. The TLM-MAO coating included anatase, rutile, $\mathrm{CaP}$ and $\mathrm{Nb}_{2} \mathrm{O}_{5}$, whereas the TC4-MAO coating included anatase, rutile, $\mathrm{CaP}$ and brookite. The $\mathrm{Ca}$ and $\mathrm{P}$ contents of the TLMMAO coating were higher than those of TC4, which had better biocompatibility. Furthermore, the corrosion resistance of the two kinds of coatings was estimated by potentiodynamic polarization curves and the electrochemical impedance spectrum in $\mathrm{SBF}$ (simulated body fluid). By analysing the selfcorrosion current density, impedance and equivalent circuit model, it was found that the corrosion resistance of the TC4 micro-arc oxidation coating, which mainly depends on the dense layer, is better than that of the TLM-MAO sample.

Keywords: Micro arc oxidation; Corrosion resistance; Coating

\section{FULL TEXT}

(C) 2019 The Authors. Published by ESG (www.electrochemsci.org). This article is an open access article distributed under the terms and conditions of the Creative Commons Attribution license (http://creativecommons.org/licenses/by/4.0/). 